\title{
Leiomyosarcoma and Endometrial Stromal Sarcoma pN0 TNM Finding v7
}

National Cancer Institute

\section{Source}

National Cancer Institute. Leiomyosarcoma and Endometrial Stromal Sarcoma pNO

TNM Finding v7. NCI Thesaurus. Code C89598.

No regional lymph node metastasis. (from AJCC 7th Ed.) 